\title{
Classification of French maize populations based on morphological traits
}

\author{
B Gouesnard ${ }^{\text {* }}$, J Dallard ${ }^{1}$, A Panouillé $^{2}$, A Boyat $^{1}$ \\ ${ }^{I}$ UFR GAP, Inra, domaine de Melgueil, 34130 Mauguio, France \\ ${ }^{2}$ Inra, Domaine expérimental du maïs, 40590 Saint-Martin-de-Hinx, France
}

(Received 3 March 1997 ; accepted 20 January 1998)

\begin{abstract}
Summary - The genetic variability of the whole collection of 262 maize populations originating from metropolitan France was evaluated in two locations for agro-morphological traits. The most important variables in the principal component (PC) axis were related to maturity traits, and ear and grain shapes. On the first plane of the PC analysis, the distribution of populations was continuous, and populations from some particular regions were found grouped together: Pyrenees (early material and conical ears), Alsace (cylindrical ears), Bresse (mostly small kernels), Vallée de la Garonne (late material with long ears or with small kernels). The two distance matrices among populations calculated on the first four PC and on the geographic coordinates were correlated. Based on the first four standardized PC axes, which accounted for $77 \%$ of the variability, hierarchical classifications were computed and dendrograms confirmed the magnitude of maturity traits, and ear and kernel shapes in the classification.
\end{abstract}

\section{Zea mays $\mathrm{L}$ / landraces / genetic resources / classification}

Résumé - Classification des populations françaises de maïs basée sur les caractères morphologiques. L'ensemble des 262 populations originaires de France métropolitaine conservées dans la collection Inra-Promais a été étudié. La variabilité génétique a été évaluée en deux lieux pour les caractères agromorphologiques (précocité, épi, grain, panicule). Les variables déterminant les axes sont, dans l'ordre : la précocité, les formes de l'épi et du grain. Sur le premier plan de l'analyse en composantes principales, la répartition des populations est continue et les populations de quelques régions se regroupent avec des caractéristiques particulières : Pyrénées (matériel précoce à épi conique), Alsace (épi cylindrique), Bresse (petit grain pour la majorité), Vallée de la Garonne (matériel tardif à épi long ou à petit grains). Les matrices de distance entre populations calculées sur les coordonnées des axes de l'analyse en composantes principales et sur les coordonnées géographiques sont corrélées. À partir des quatre premiers axes standardisés de l'analyse en composantes principales représentant $77 \%$ de variabilité, des analyses ascendantes hiérarchiques ont été effectuées. Les dendrogrammes confirment l'importance de ces caractères dans la classification.

Zea mays L / populations locales/ ressources génétiques / classification

Article communicated by André Gallais (Gif-sur-Yvette)

* Correspondence and reprints

Tel: (33) 04672906 17; fax: (33) 04672939 90; email: gouesnard@ensam.inra.fr 


\section{INTRODUCTION}

Maize cultivation in France started in the 'Pays Basque' and 'Béarn' and was reported for the first time in 1536 by Jean Ruel (Gay, 1984). Maize cultivation in France spread at the end of the 16th century. Traditional regions of maize cultivation are the south-west part of France (from the Pyrenees to the Garonne Valley) and also the north-east (Alsace and Bresse). These regions, characterized by rainy summers, are all favorable for maize cultivation.

Maize populations cultivated in France were first described in 1785 by Parmentier (Gay, 1984), and then by Bonafous (1836). The catalogue of open-pollinated maize varieties cultivated in France has been well known since the 1930s. Among the well-known and widespread varieties, Jaune d'Alsace, Étoile de Normandie, Blanc and Jaune de Bresse and Jaune Hatif d'Auxonne are early maturity varieties; Blanc de Chalosse, Maïs de Tarbes and Doré des Landes are medium-early maturity varieties; Maïs de Pouyastruc and Roux de Chalosse are medium-late maturity varieties; and Doré de Gomer, Millette de Lauragais, Millette du Finhan are late maturity varieties (Gay, 1984).

Today only hybrid varieties are cultivated in France. Cultivation of American hybrids started in 1948 with the 'Marshall Plan'. Soon after, early and adapted inbred lines were developed from European populations. Hybrids between early European and American inbreds were cultivated and began to spread to regions where maize was not cultivated before. For instance, the inbred line F2 was obtained in 1952 from the Lacaune population and led to the development of early French $\times$ American hybrids such as Inra258.

Soon after the introduction of American hybrids, breeders became interested in the vari- ability of maize populations. The collection of maize populations began in 1945-1946 mainly to develop inbred lines under the direction of Professor Alabouvette. A large collection of French populations was constituted in the early 1960s by an Inra researcher, A Cauderon.

Since 1983, a programme has been undertaken under the direction of Professor Gallais. This programme involves Inra and the association of maize breeders in France (Promais) in order to study maize populations adapted to French conditions and to improve their use. New accessions were collected at the beginning of the programme. A total of 1236 populations or synthetics were reconducted and evaluated for the combining ability of grain and silage production and for the per se value of other traits (Gallais et al, 1992; Groupe Inra DGAP and Promais, 1994).

The objectives of this study were to 1) evaluate the genetic variability of French populations, 2) try to establish a classification based on morphological traits, 3) study the relationship between geographical origin and variability of maize populations.

\section{MATERIALS AND METHODS}

\section{The collection of French maize populations}

The collection of 262 populations originating from metropolitan France is stored in the Inra-Promais genebank in the Inra Research Unit at Mauguio (France). In this study, all French maize populations were analysed. The list of the populations is given in the Index Seminum of the Inra Research Unit (Meynie, 1992).

The distribution of populations according to the administrative regions of France is given in table $\mathbf{I}$. Three quarters of these populations originate from the south-west of France. Climatic conditions in the south-

Table I. Distribution of the populations according to administrative regions of France with an indication of the tradional maize growing regions.

\begin{tabular}{llcc}
\hline Administrative Regions & Traditional maize regions & Number & Percentage \\
\hline Picardie, Nord & & 7 & 2.7 \\
Alsace & Alsace & 12 & 4.6 \\
Bourgogne, Rhône-Alpes & Bresse, Isère,... & 29 & 11.1 \\
Languedoc, Provence & & 4 & 1.5 \\
Midi-Pyrénées & Pyrenees, Vallée de la Garonne,... & 112 & 42.7 \\
Aquitaine & Chalosse, Béarn, Pays Basque,... & 45 & 32.4 \\
Limousin & & 9 & 1.5 \\
Poitou-Charentes & & 9.5 \\
\hline
\end{tabular}


west vary from highland (Pyrenees) to valley conditions (Garonne valley). Five percent originate from Alsace (north-east part of France) and $10 \%$ originate from the central eastern part (Bresse, Dijon). These two regions are traditional maize growing areas with a continental climate.

\section{Experimental design}

The 262 populations were all sown in 1993 and 1995 in two Inra maize stations: Mauguio (near Montpellier) and Saint-Martin-de-Hinx (near Bayonne). The populations were distributed into six earliness groups and randomized within the groups. In 1993, the experimental design had one replicate with a two-row plot of 20 plants. In 1995, the experimental design had two replicates with a one-row plot. The sowing density was 46000 plants per ha.

The data were recorded in two sets: plant and ear traits in 1993 and grain and tassel traits in 1995 (table II). The data were taken from ten competitive plants. Two grains per ear were measured for each plot.

The kernel colour value of the populations was obtained by weighting the different coloured parts of the sample by their frequencies. The scale ranged from 1 for white to 8 for purple. The kernel texture was also noted by weighting the different parts of the sample with a scale from 1 for flint to 9 for dent. We used the conicity index defined by Ordas and de Ron (1988).

\section{Statistical analysis}

Analyses of variance were used to test the significance of variation among populations for each trait. For a trait recorded in 1993, the model of analysis of variance was:

$$
Y_{i j k}=\mu+\alpha_{i}+\beta_{j}+\gamma_{j k}+\xi_{i j k}
$$

where $Y_{i j k}$ is the observed value of population $k$ belonging to the earliness group $j$ in the location $i$. $\mu$ is the average of the experiment, $\alpha_{i}$ is the location effect; $\beta_{j}$ is the effect of the earliness group; $\gamma_{j k}$ is the population effect within the earliness group effect; $\xi_{i j k}$ is the interaction effect of location $i$ by population $k$ within group $j$ which can be considered as the error associated with the $Y_{i j k}$ observation.

For a trait recorded in 1995, the model of analysis of variance was:

$$
Y_{i j k l}=\mu+\alpha_{i}+\beta_{j}+\lambda_{i j}+\gamma_{j k}+\delta_{i l}+\phi_{i j k}+\xi_{i j k l}
$$

where $Y_{i j k l}$ is the observed value of population $k$ (from the earliness group $j$ ) in the location $i$ at the replicate $l$. $\mu$ is the average of the experiment; $\alpha_{i}$ is the location effect; $\beta_{j}$ is the effect of the earliness group; $\lambda_{i j}$ is the interaction effect between location and earliness group; $\gamma_{i k}$ is the population effect within the earliness group effect; $\delta_{i l}$ is the replicate within the location effect; $\phi_{i j k}$ is the interaction effect between the location and the population within earliness group; $\xi_{i j k l}$ is the error associated with the $Y_{i j k l}$ observation.

These analyses of variance make it possible to estimate genotypic and environmental variances (error and interactions). Heritability in the broad sense was estimated for each morphological trait.

The correlation coefficients between traits were estimated from the mean value of populations over locations. Some ratios between two traits expressing the shape of some plant parts were added to the correlation matrix. These ratios were kept in the study instead of one of the traits when the correlation coefficient esti-

\begin{tabular}{|c|c|c|c|}
\hline Abbreviation & Trait & Year & Active traits \\
\hline TFLF & accumulative degree-days to silking (base $6^{\circ} \mathrm{C}$ ) & 1993 & 1 \\
\hline HEPI & ear height $(\mathrm{cm})$ & 1993 & 1 \\
\hline LE & ear length $(\mathrm{mm})$ & 1993 & 1 \\
\hline DIAM & ear diameter $(\mathrm{mm})$ & 1993 & 1 \\
\hline CONI & ear conicity index & 1993 & 1 \\
\hline NRG & ear row number & 1993 & 1 \\
\hline Pl0000G & 1000 kernels weight $(\mathrm{g})$ & 1993 & 1 \\
\hline COULEUR & kernel colour (scale 1 to 9 ) & 1993 & 1 \\
\hline TEXTURE & kernel texture (scale 1 to 9 ) & 1993 & 0 \\
\hline $\mathrm{LO}$ & kernel length (mm) & 1995 & 1 \\
\hline LA & kernel width $(\mathrm{mm})$ & 1995 & 0 \\
\hline LOLA & kernel length / kernel width & 1995 & 1 \\
\hline LSOM & tassel length $(\mathrm{cm})$ & 1995 & 1 \\
\hline BRANCHE & tassel branch length $(\mathrm{cm})$ & 1995 & 0 \\
\hline BRANSOM & tassel branch length / tassel total length & 1995 & 1 \\
\hline MAITRE & central spike length of tassel $(\mathrm{cm})$ & 1995 & 1 \\
\hline NRAM 1 & number of primary branches & 1995 & 1 \\
\hline NRAM2 & number of secondary branches & 1995 & 0 \\
\hline DENSRAM & tassel branch number / tassel branch length & 1995 & 1 \\
\hline
\end{tabular}

Table II. List of the traits, the traits included in the principal component analysis are indicated by 1 in the last column. 
mate with another trait was lower than with the considered trait. Thus, the ratio of kernel length to kernel width was retained instead of kernel width which was highly correlated with kernel weight. Similarly, the ratio of the branch tassel length to the total tassel length was kept instead of tassel branch length, and the ratio of tassel branch number to tassel branch length was kept instead of secondary branch number. A total of 15 variables were studied (table II).

A principal component analysis was carried out on the correlation matrix of the 15 traits using the Princomp procedure from SAS package (SAS, 1987). The 17 populations that were not entirely flint were considered as supplementary individuals. They have probably been recently introgressed by American dent germplasm.

The principal components with an eigenvalue higher than one were used for performing cluster analysis. Axes were standardized to reduce the relative contribution of the first axis which mainly involved maturity traits. Euclidean distance was calculated upon the four first standardized principal components. This distance called 'Mahalanobis generalized distance' was used by Llaurado and Moreno-Gonzalez (1993).

For the populations with a well-known collection site, the geographical distance between populations was calculated on the geographical coordinates (longitude and latitude in Lambert coordinates). The Mantel (1967) test was computed to compare the morphological and geographic distance matrices on a sample of 98 randomly chosen populations.
We carried out a cluster analysis using the unweighted pair group method based on arithmetic averages (UPGMA) using the Cluster procedure of SAS (1987). The Euclidiean distances among populations calculated on the first four standardized axes among populations were computed in this procedure. Dendrograms showing the phenetic relationships among populations were obtained by the TREE procedure of SAS (1987) and GRFTREE software (Jacobs, communicated by Internet in 1995). The choice of the number of clusters was based on the pseudo $\mathrm{F}$ and $\mathbf{t}^{2}$ statistics (SAS, CLUSTER procedure option).

\section{RESULTS AND DISCUSSION}

\section{Univariate analysis of variance}

Significant variation existed among locations and among populations for all traits (table III). For the traits studied in 1995, the interaction effect between location and population within the earliness group was also tested, and was significant for all traits.

The traits with the highest heritability were kernel width and ear row number. This result is consistent with previous results published on maize populations (Goodman and Paterniani, 1969; Llaurado and Moreno-Gonzalez, 1993). The traits

Table III. F values for location (loc), earliness group (earl), location $\times$ earliness group, population, location $\times$ population effects, mean square (MS) error, and estimates of heritability.

\begin{tabular}{|c|c|c|c|c|c|c|c|c|}
\hline Year & Variable & Floc & F earl & Floc $\times$ earl & F pop(earl.) & $F l o c \times p o p$ & MS error & Heritability \\
\hline 1993 & CONI & 0.16 & $17.18 * *$ & $10.26 * *$ & $6.19 * *$ & - & 0.376 & 0.84 \\
\hline 1993 & DIAM & $205.49 * *$ & $16.56 * *$ & $7.87 * *$ & $11.49 * *$ & - & 2.223 & 0.91 \\
\hline 1993 & FLF & $1976.84 * *$ & $1394.93 * *$ & $11.35 * *$ & $7.8 * *$ & - & 1.918 & 0.87 \\
\hline 1993 & TFLF & $187.44 * *$ & $1127.8 * *$ & $12.86 * *$ & $6.66 * *$ & - & 475.923 & 0.85 \\
\hline 1993 & HEPI & 3.39 & $125.62 * *$ & 1.79 & $4.25 * *$ & - & 98.287 & 0.76 \\
\hline 1993 & LE & $318.23 * *$ & $113.41 * *$ & $6.6 * *$ & $7.2 * *$ & - & 93.458 & 0.86 \\
\hline 1993 & NRG & $34.76 * *$ & $620.11 * *$ & $3.59 * *$ & $24.74 * *$ & - & 0.522 & 0.96 \\
\hline 1993 & P1000G & $179.35 * *$ & $284.89 * *$ & 1.78 & $12.35 * *$ & - & 863.292 & 0.92 \\
\hline 1995 & BRANCHE & $452.51 * *$ & $209.88 * *$ & $5.03 * *$ & $9.51 * *$ & $1.38 * *$ & 1.854 & 0.85 \\
\hline 1995 & BRANSOM & $515.18 * *$ & $121.04 * *$ & $6.12 * *$ & $6.96 * *$ & $1.2 *$ & 0.001 & 0.83 \\
\hline 1995 & DENSRAM & $356.84 * *$ & $154.27 * *$ & $7.58 * *$ & $7.11 * *$ & $1.51 * *$ & 0.028 & 0.79 \\
\hline 1995 & LA & $218.68 * *$ & $2024.47 * *$ & $8.86 * *$ & $78.16 * *$ & $1.8 * *$ & 9.234 & 0.98 \\
\hline 1995 & LO & $332.75 * *$ & $13.08 * *$ & $12.35 * *$ & $18.45 * *$ & $1.48 * *$ & 9.748 & 0.92 \\
\hline 1995 & LOLA & $13.97 * *$ & $1730.65 * *$ & $4.5 * *$ & $52.52 * *$ & $1.45 * *$ & 0.001 & 0.97 \\
\hline 1995 & LSOM & $5.4 *$ & $223.64 * *$ & 2.08 & $11.56 * *$ & $1.73 * *$ & 6.828 & 0.85 \\
\hline 1995 & MAITRE & $183.52 * *$ & $86.97 * *$ & $14.32 * *$ & $5.88 * *$ & $1.24 * *$ & 3.189 & 0.79 \\
\hline 1995 & NRAM 1 & $843.68 * *$ & $509.01 * *$ & $11.04 * *$ & $9.45 * *$ & $1.76 * *$ & 3.222 & 0.81 \\
\hline 1995 & NRAM2 & $892.26 * *$ & $200.76 * *$ & $19.06 * *$ & $11.08 * *$ & $2.56 * *$ & 0.942 & 0.77 \\
\hline
\end{tabular}

*,** Significant at $P<0.05,0.01$, respectively. 
with the lowest heritability were ear height and conicity index. However, the heritability values were high (higher than 0.75).

\section{Principal components analysis}

\section{Distribution of variables}

The first four principal components (PC) accounted for $77 \%$ of the total variance (table IV). In the first PC, earliness, number of primary branches, ear height and kernel shape were the most important traits. The second PC described variations in the ear traits, showing an opposition between long cylindrical ears and short conical ears. In the third PC, kernel traits (weight of 1000 kernels and kernel length) were the most important. In the fourth $\mathrm{PC}$, the central spike length of the tassel and the ear diameter were predominant.

These results underline that earliness and plant size are the traits that contribute the most to the phenotypic variation among French populations. This result is classic since earliness is the main trait for maize adaptation. Earliness was followed in order of importance by traits related to ear and grain shapes. Similarly, on Spanish maize populations, Llaurado and Moreno-Gonzalez (1993) and Ordas et al (1994) also found that traits related to ear shape were in second place, followed by grain shape traits and then by tassel traits. Melchiorre (1992) found the same general order of traits in Argentinian populations. However, grain shape and grain weight traits were more important than ear shape traits in the classification of Italian maize populations (Camussi, 1979). For the French populations and the Spanish populations studied by Llaurado and Moreno-Gonzalez (1993), grain weight contributed to the first axis less than maturity traits and had a large influence on the third axis. In our study, the Pyrenean populations, which have early maturity and large kernels, tended to enhance the correlation between earliness and kernel weight. Tassel shape did not contribute as much to the discrimination between populations. The discrimination value of a trait depends on the historical origin and the genetic background of the population. Adaptation to climatic conditions for earliness, farmer selection for ear and grain shapes and texture, the genetic background and random drift seem to have contributed to the variability observed among French populations.

Earliness traits are highly correlated with height traits and are very important for the classification
Table IV. Eigenvectors, eigenvalues and cumulated total variation of the first four principal components.

\begin{tabular}{lrrrr}
\hline Variables & AXIS I & AXIS 2 & AXIS 3 & AXIS 4 \\
& & & & \\
\hline HEPI & 0.33 & 0.14 & 0.24 & -0.04 \\
LE & 0.25 & -0.33 & 0.23 & 0.05 \\
CONI & -0.10 & 0.47 & -0.13 & 0.29 \\
DIAM & -0.02 & 0.36 & 0.13 & 0.57 \\
LOLA & 0.34 & 0.05 & -0.33 & 0.00 \\
P1000G & -0.29 & 0.14 & 0.43 & 0.07 \\
LO & -0.03 & 0.25 & 0.38 & 0.09 \\
LSOM & 0.20 & -0.29 & 0.35 & 0.26 \\
MAITRE & 0.11 & -0.37 & 0.00 & 0.58 \\
BRANCHE & 0.26 & 0.17 & 0.35 & -0.28 \\
COULEUR & -0.04 & -0.17 & -0.03 & -0.07 \\
TFLF & 0.41 & -0.06 & 0.05 & 0.04 \\
NRAM1 & 0.39 & 0.19 & 0.16 & -0.11 \\
DENSRAM & 0.30 & 0.32 & -0.11 & -0.10 \\
NRG & 0.31 & 0.09 & -0.36 & 0.26 \\
Eigenvalue & 5.01 & 2.67 & 2.51 & 1.42 \\
Cumulated & & & & \\
variation & 33.42 & 51.24 & 67.98 & 77.48 \\
\hline
\end{tabular}

of maize populations. These traits are heritable and can be selected quite easily. Maize populations with the same genetic background may have different earliness. Therefore in population classification, it seems interesting to balance the importance of shape traits with earliness and height traits by standardizing the principal components.

\section{Distribution of populations and geographic origin}

The distribution of populations on the plane of the first two principal components was continuous. A large part of the populations having the same geographical origin was grouped together, even though the other populations belonging to the same geographical region were scattered on the plane (fig 1). Populations from the Pyrenees (mountain climate) had early maturity and large kernels (upper left part of the plane). Populations from Alsace (continental climate) had medium maturity and cylindrical ears (lower left part of the plane). Populations from Bresse (continental climate) showed two morphological types: one had small kernels (lower right part of the plane) and the other had later plants and heavier kernels (scattered in the right part of the plane). In this region, maize with small kernels is used for poultry feeding. Late maturity populations, mainly originated from valley regions (Garonne valley), were located on the upper right of the plane. The distribution 


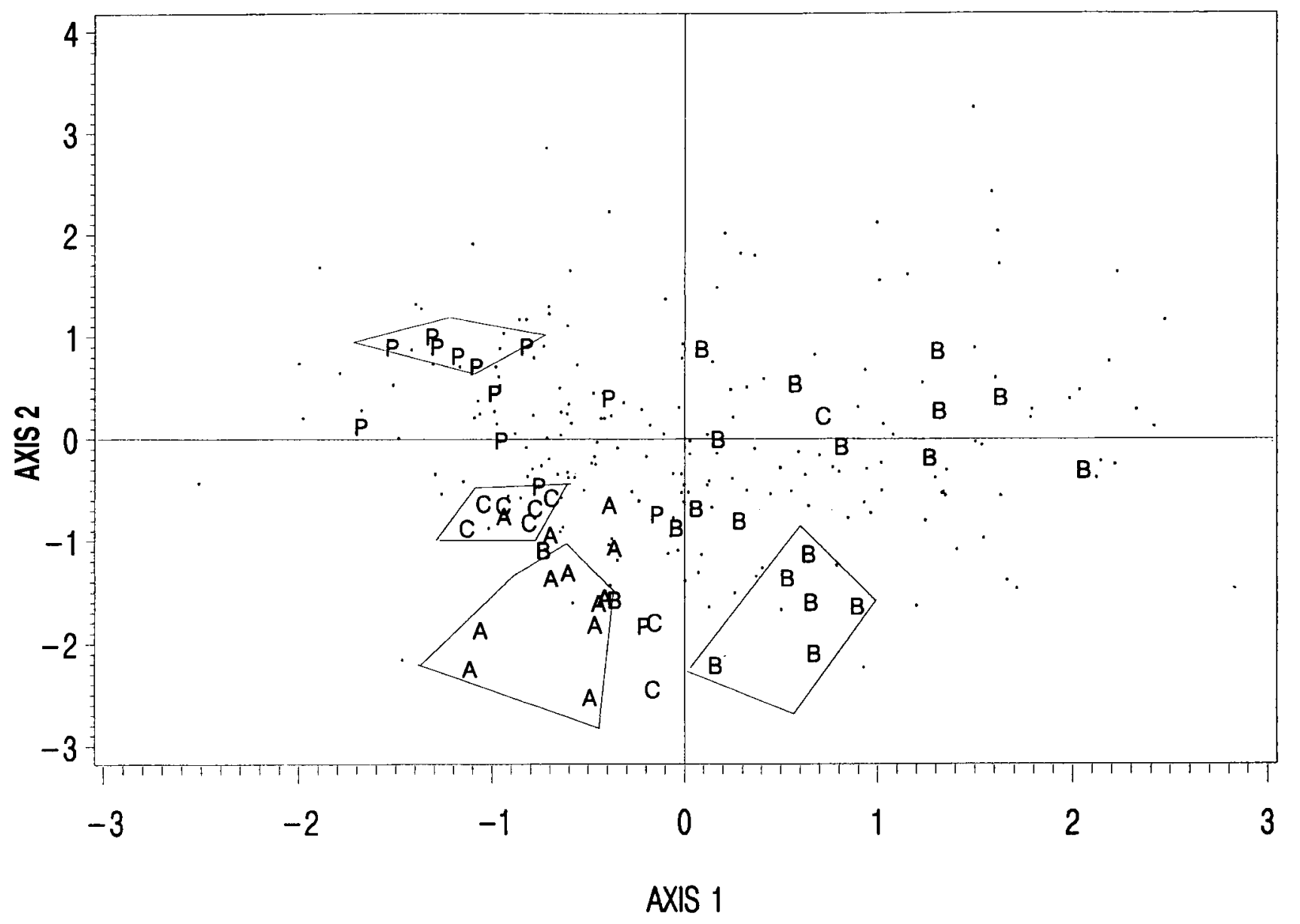

Fig 1. Plot of the first plane of principal component analysis with the populations from Alsace (A), Bresse (B), Charentes (C), Pyrenees $(\mathrm{P})$. A line is drawn around the most representative populations of a given region. For Bresse, surrounded populations are characterized by small kernels.

of the 'geographical centres' on the first axis shows a gradient from highland (Pyrenees), Chalosse and Piedmont region (groups not shown), to valley regions (Garonne valley). On the second axis, populations from eastern France were separated. Populations from Charentes (central west of France) were relatively close to Alsace populations.

The Mantel (1967) test was computed in order to compare two Euclidean distance matrices, one based on the four first axes of principal component analysis (morphological traits) and the second based on geographical co-ordinates (longitude and latitude in Lambert co-ordinates). The estimate of the correlation coefficient was 0.7 for 98 randomly chosen populations. The relationship between distance based on morphological data and geographical co-ordinates was confirmed by Mantel's test.

\section{Cluster analysis}

The UPGMA cluster analysis (fig 2) generated many small clusters. Some populations of the
Inra-Promais collection exhibited special traits, such as high conicity index, tassel shape, ear shape. These populations were separated rapidly from the rest of the collection in the dendrogram. The cluster analysis distinguished 15 clusters with five principal clusters:

Group 1 included medium-early populations. The size of this group was very large: 151 populations from the south-west, Alsace, Charentes.

Group 2 included medium-early populations with small kernels: 23 populations. Most of these populations originate from Bresse.

Group 3 consisted of early populations: 23 populations, from all part of France.

Group 4 consisted of late populations with short ear diameter: 10 populations, mainly from the Pyrenean Piedmont.

Group 5 consisted of late populations with conical ears: 21 populations, from the south-west not including the Pyrenean Piedmont. 


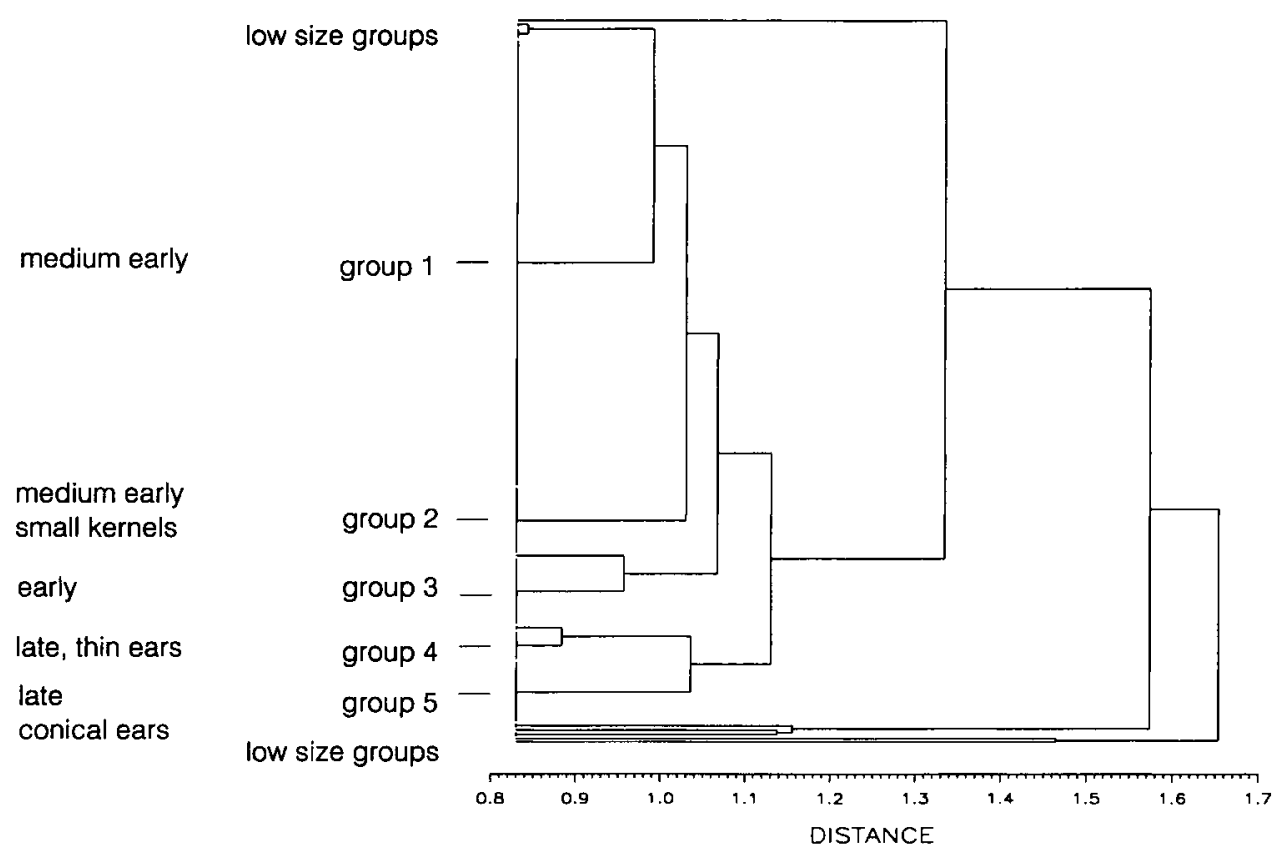

Fig 2. Average linkage dendrogram of the 245 maize populations from France based on Euclidian distance on the first four standardized principal component axes.

The UPGMA procedure was consistent in grouping maize populations (Ajmone-Marsan et al, 1992; Melchiorre, 1992; Mumm and Dudley, 1994; Ordas et al, 1994). The Ward cluster analysis builds clusters of similar size, and tends to divide dense clusters in an acceptable manner [Sneath and Sokal cited by Rincon et al (1996)]. The Ward method was the best strategy when the size of groups was similar (Franco et al, 1997). On inbred lines analysed by RFLP probes, the Ward procedure gave a classification consistent with pedigree (Dubreuil et al, 1996); however the UPGMA procedure also gave an adequate classification (Dubreuil, pers comm). On a Caribbean collection, Rincon et al (1996) found lower cophenetic correlation coefficients with the Ward method than with the UPGMA method.

The 151 populations of group 1 obtained by UPGMA analysis were subdivided into several groups by Ward analysis. For example, Alsace populations were separated from Charentes populations in the Ward method. For groups 2-5 (fig 2), the two procedures give similar clusters with more than $50 \%$ of populations common to the two classifications.

\section{CONCLUSION}

In comparison with the open-pollinated varieties of maize cultivated in the 1930s (Gay, 1984), the Inra-Promais collection (table I) is highly representative of Pyrenean and poorly representative of northern populations. Representativeness of other regions is adequate.

Rautou (1953) gave a classification of 120 French maize populations. The main criteria of classification were maturity (early, medium early, late groups) and an indication of the geographical origin of the populations (Jaune d'Alsace, Maiis de Bresse and du Jura, Blanc de Chalosse, etc). The 17 groups were described by plant height, ear, grain and cob shapes.

Our data also show the predominance of maturity traits in the classification of maize and a good relation between the geographical distance matrix and the morphological distance matrix. This high correlation between geographical distances and morphological distances can be related to a large extent to adaptation to various climatic conditions in France (continental climate in Alsace, Piedmont conditions in Bearn, mountain climate in Pyrenees, Atlantic conditions in Chalosse). However, the geographical origin of a population does not indicate its morphological type. In the same region, different types of maize could be cultivated for different uses (feeding poultry, cattle or humans) and under various microclimatic conditions (from valley to high elevations). Thus, a few populations from Bresse have a medium-late maturity and most of them have a high ear row number with very small kernels (group 2). Late populations called Millette also have two phenotypes, one with long ears (group 4) and the other with conical ears with a high row number and small kernels (group 5). Maize with small kernels were used for poultry feeding in Bresse and in the 
south-west. These descriptions of regional groups of maize populations are consistent with Rautou's descriptions. Analysing the relationship between geographical data and morphological data also has to take into account that the geographical origin is not always well known. The seeds could be provided from another region (via merchants, for example).

The classification of French maize populations is based on maturity traits related to geographical origin, and ear and grain shapes. The ear and grain shapes were not the primary criterion. This criterion was retained by Brandolini for the European maize population classification, after having given a description of the main climates in Europe (Brandolini, 1969, 1970). Likewise, SanchezMonge (1962) based the description of Spanish races mainly on ear shape after having given their geographical location. To classify American maize populations, Goodman and Bird (1977) used mainly ear and grain shape. Llaurado and Moreno-Gonzalez (1993) emphasized the taxonomic value of maturity traits and the force of adaptation to different climatic conditions for northern Spanish populations.

Our results show that the distribution of populations on the first four axes of the principal components analysis, which accounted for $77 \%$ of total variability, was consistent with previous classifications of French maize populations. The classifications obtained either by UPGMA or Ward procedures were not very stable. The limits between clusters were not always the same when different sets of variables were chosen for the analysis. This result (data not shown) is consistent with the continuous distribution of populations on the first plane of the principal component analysis. Although the clusters obtained from UPGMA or Ward procedures were built in the same manner (differentiation on length kernel, ear row number, ear shape, etc) and some populations were always grouped together, the dendrograms are different.

\section{REFERENCES}

Ajmone Marsan P, Livini C, Melchinger AE, Messmer M, Motto M (1992) Cluster analysis of RFLP data from related maize inbred lines of the BSSS and LSC heterotic groups and comparison with pedigree data. Euphytica 60, 139-148

Bonafous M (1836) Histoire naturelle agricole et économique du maïs. Paris, $190 \mathrm{p}$.

Brandolini AG (1969) European races of maize. Proc 24th Ann Corn and Sorghum Research Conference $36-48$
Brandolini AG (1970) Razze Europee di mais. Maydica $15,5-27$

Camussi A (1979) Numerical taxonomy of Italian populations of maize based on quantitative traits. Maydica 24, 161-174

Dubreuil P, Dufour P, Krejci E, Causse M, Devienne D, Gallais A, Charcosset A (1996) Organization of RFLP diversity among inbred lines of maize representing the most significant heterotic groups. Crop Sci 36, 790-799

Franco J, Crossa J, Villasenor J, Taba S, Eberhart SA (1997) Classifying Mexican maize accessions using hierarchical and density search methods. Crop Sci 37, 972-980

Gallais A, Duval H, Garnier P, Charcosset A (1992) Un exemple de gestion des ressources génétiques en vue de la selection. In: Actes du colloque en hommage à Jean Pernès: complexes d'espèces, flux de gènes et ressources génétiques des plantes, BRG, Paris.

Gay JP (1984) Fabuleux maïs. AGPM, Pau, France

Goodman MM, Bird MK (1977) The races of maize. IV. Tentative grouping of 219 Latin America races. Econ Bot 31, 204-221

Goodman MM, Paterniani E (1969) The races of maize. III. Choices of appropriate characters for racial classification. Econ Bot 23, 265-273

Groupe maïs DGAP-Inra and Promaïs.(1994) Cooperative program for management and utilization of maize genetic resources. In: Evaluation and Exploitation of Genetic Resources Pre-breeding. Proceedings of the genetic resources section meeting of EUCARPIA. Clermont-Ferrand, France

Llaurado M, Moreno-Gonzalez J (1993) Classification of northern Spanish populations of maize by numerical taxonomy. I. Morphological traits. Maydica 38, 15-21

Mantel N (1967) The detection of disease clustering and a generalized approach. Cancer Res 27, 209-220

Melchiorre P (1992) Phenetic relationships among different races of maize (Zea mays sss mays) from Salta (Argentina). Maydica 37, 329-338

Meynie S (1992) Index seminum. Inra SGAP, Montpellier

Mumm RH, Dudley JW (1994) A classification of 148 U.S. maize inbreds.1. Cluster analysis based on RFLPs. Crop Sci 4, 842-851

Ordas A, De Ron AM (1988) A method to measure conicalness in maize. Maydica 33, 261-267

Ordas A, Malvar RA, De Ron AM (1994) Relationships among American and Spanish populations of maize. Euphytica 79, 149-161

Rautou S (1953) Populations de pays et hybrides de maïs. Agriculture 7-11

Rincon F, Johnson B, Crossa J, Taba S (1996) Cluster analysis, an approach to sampling variability in maize accessions. Maydica 41, 307-316

Sanchez-Monge E (1962) Razas de maiz en Espana. Madrid

SAS Institute Inc. (1987) SAS/STAT user's guide. SAS Institute Inc. Cary, NC, USA 